\title{
Research on Applications of Humanism Management Thoughts and Positive Incentive on Contemporary Enterprise Management Activities
}

\author{
Gefei Sun ${ }^{1}$ \\ ${ }^{1}$ Henan Economy and Trade Vocational College, \\ Zhengzhou,Henan,China
}

\begin{abstract}
In this paper, we conduct research on the applications of humanism management thoughts and positive incentive on contemporary enterprise management activities. The success or failure of an enterprise, it has connected with the enterprise staff. Modern enterprise to make the enterprise in the competitive market of the brand is enduring, its survival is to be active play to the initiative, enthusiasm and creativity of employees, emphasizing the subject status of the employees and the leading role which is to emphasize the importance of basic management in enterprise management. Our research provides managers with the state-of-the-art methodology of management which will enhance the overall performance and the efficiency of business operating.
\end{abstract}

Keywords: Humanism Management; Positive Incentive; Enterprise Management Activities.

\section{Introduction}

Since reform and opening up, China's economy is developing at an unprecedented rate. Enterprise is an important component of the socialist economy. It is the important basis for the development of national economy patterns. In the modern market economy under the background of the national economic management is an urgent need to modern update. To make the economy better and faster development forward and in order to realize the modernization management of the national economy will first start from the implementation of modern enterprise management. The realization of the modernization of enterprise management, modern management idea, management mode, modern management methods, and conform to the times development management mode is the most basic conditions [1]. Management mode of the first factor is culture, we must establish the suitable management mode, China will contemporary management science are rooted in national culture, through the combination of advanced theory and traditional culture, the construction management mode suitable for local characteristics. The second influence factor is the social and political system, our country is a socialist, so in the enterprise management, the interests of the employees respect and dignity need to be the biggest, the most widely staff to participate in the management at the same time, the maximum play to their enthusiasm and creativity, the handle of the relationship between efficiency and equity at the same time, establish a new type of leadership style. National conditions and the environment is the third influence factors, specifically including the social and economic foundation, economic situation, development stage, the social psychological status, social environment should be in accordance with the general national conditions in our country enterprise management and the transformation to adjust the management mode of the surroundings.

Modern enterprise management mode reform and innovative measures could be summarized as the follows. (1) Strengthened enterprise's timing and strategic management. The concept of enterprise management model innovation should strengthen the timeliness and strategic enterprise 
management, in order to improve the management level of enterprises. At present, the modern enterprise is not only to summarize experience of enterprise management in our country, should also absorb the concept of foreign some advanced enterprise management mode. However, many enterprises in our country is just follow the successful management of the management idea, but not attach great importance to the idea innovation of enterprise management mode, this kind of situation not only help enterprises to better development which can also affect the enterprise's management level. Therefore, the choice of modern enterprise management mode which must have certain timeliness and strategic, enterprise managers should be able to apply, to further strengthen innovation and development of the concept of enterprise management mode in our country. (2) Practical inspection standards system is established. The reform and innovation of modern enterprise management mode of the first to establish a practical test system, mainly due to the reform and innovation of enterprise management mode must pass strict inspection. The innovation of the modern enterprise management mode, of course, should also give full consideration to the national policy factors, social and cultural factors and the structure of the enterprise to promote the reform of the enterprise management mode is more successful. (3) Set up the competitive management concept. Along with country market economy increasingly competitive, modern enterprises should establish competitive management mode, to improve the management level of modern enterprise [2]. Modern enterprise is facing the rapid changing market conditions, factors influencing the economic efficiency of enterprises more and more complex. (4) Set up development of people-oriented concept. With the rapid development of science and technology, the reform and innovation of modern enterprise management mode should first set up the text of the concept of enterprise development to people.
So, now more and more enterprises have the management mode of reform and innovation as the core of enterprise development.

In this paper, we conduct research on the applications of humanism management thoughts and positive incentive on contemporary enterprise management activities. We found through scientific research and a lot of practice to realize the modernization of enterprise management is the enterprise survival and development under the background of new economy inherent requirement and eternal subject. During the course of the future development, the enterprise should follow the trend of the development of modernization, pay attention to the innovation of management idea, choose suitable for the own development needs of management mode and accelerate the process of modernization of enterprises and make the enterprise itself better and faster integration into the mainstream of modern economy. In the following sub-sections, we will discuss the issues in detail.

\section{The Proposed Methodology}

The Humanism Management Thoughts. Humanistic management idea is to put the employees as the most important resource of enterprise, to the staff's capabilities, skills, interests, psychology and so on comprehensive situation to arrange the most suitable job scientifically, and fully considering the employees in the work of growth and value, using scientific management methods, through comprehensive human resource development program and the enterprise culture construction. Enable employees to fully mobilize and play in work enthusiasm, initiative and creativity, thereby improving the work efficiency, increase the work performance, make greatest contribution to achieve enterprise development. The meaning of humanistic management could be summarized as the follows. (1) In the production and operation practice, people realize more and more, decided to an enterprise, a social 
development ability, the main is not the machine equipment, but what they have knowledge and wisdom, talent and skill. People is the main part of the social economic activities, is the most important resource of all resources [3]. In the final analysis, all economic activities, is carried out by people. Lack of activity of people, there will be no vitality and competitiveness and therefore must be set up, relying on the management idea of people, through the joint efforts of all staff, to create the brilliant achievements of the enterprise. (2) Companies with the highest operating purposes. Each individual as a capital ordinary employees, are people with independent personality, is human dignity and human rights. Whether the east or the west, people often see dignity as a spiritual symbol is more important than life. As an enterprise, not only to respect every employee, more respect for every customer, every user. Because an enterprise can exist, it is because they are accepted and recognized by consumers, so should make every effort to satisfy consumers and feel really is god. (3) Enterprise itself is a living, every one of a molecule in living organisms, is this so, management should not only study the each member's enthusiasm, creativity and quality, the whole enterprise but also the cohesion and centripetal force, forms the powerful force of the whole. (4) The task for enterprise is how to maximize mobilize the enthusiasm of people, can release its latent and let people with great enthusiasm and creativity in business. Liberation of productive forces, the first is the liberation of the people. The reform, we are basically, it is to give full play of hundreds of millions of people's wisdom to create a good environment and mechanism. In the era of knowledge economy, decided to the enterprise successful key factor gradually in human resources. The birth of the humanistic ideas and application in the enterprise, make enterprise management to optimize the capital for the purpose of management to optimize personnel management as the goal and this is a big and meaningful improvement of modern enterprise management and maintenance ideas.

Enterprise goal setting should be highlighted to satisfy the needs of stakeholders. Attaches great importance to the human resources development management strategy and the focus of the traditional enterprise strategic management is mainly for the development of material resources. In the process of reengineering the corporation, enterprise strategy has shifted from financial capital to human capital, to develop human resources, maximize people's enthusiasm and creation Personnel management focus on creative play. The humanist management thought the main body of enterprise operation and management system is the staff. Treat employees as managers is helpful to arouse the enthusiasm of employees, and make the employees to enhance the sense of responsibility, to the enterprise can make the employees make more contribution to the development of enterprises. Enterprise policy and implement the principle of priority to efficiency and due consideration to fairness.

The harmonious interpersonal relationship will be driven the human development and actively developing human resources for the society. Human resources development throughout the whole process of human resource development, its core is to develop potential. To implement talent strategy, it is the objective requirement of the enterprise development. Cultivating and team work spirit. Humanistic management is the essential characteristics of the self-management ability. Humanistic management thought is an important theory in the history of the development of management theory innovation. At present, our country's economy is in the primary market economy to perfect market economy transition stage, the enterprise management practice urgently needs a new and feasible can effective guidance to the practice management of the new theory.

The Positive Incentive. Enterprise incentive mechanism is to point to by a rational system to 
reflect the incentive way of the interaction between the subject and incentive object. Managers in the process of incentive, to master the can affect employees, inspire staff potential technical tool, to help employees to achieve the goal, also need to know how to lead the staff to slowly learn to own. This has nothing to do with management and the leadership, the power of the development is to help others. Enterprise incentive mechanism to play a strategic role in the enterprise human resources management, but given the current problems of incentive mechanism, such as: enterprise incentive mechanism is imperfect and salary system is not sound, etc. The human capital, the enterprise will have what kind of business process and organization structure, enterprise culture and so on capital structure mainly depends on the managers of enterprises, customer resources, and relationship capital to establish and maintain relations between the government not only related to management, depends on the efforts of the staff at the local level. Therefore, the enterprise to the use and management of intellectual capital to a great extent which is a kind of incentive problems, through the appropriate means to motivate employees maximize the update and activate the intellectual capital, to increase the value of the enterprise. In intellectual capital stock of the same case, the value of different enterprise growth differences can also be explained by the difference of intellectual capital incentive.

To solve the mentioned drawback, we optimize the current model of the enterprise management with the following suggestions. (1) Incentives in order to boost the enthusiasm of the staff, is the purpose of different employees to the different requirements, the requirements of the enterprise in different stage are also different. Therefore, enterprise should according to the hierarchy of needs to establish the incentive mechanism, can according to the employees need to improve their own quality or give their self-motivation to grasp the employee requirement types, distinct incentive, not simply adopt the one size fits all. (2) Material is the basic guarantee for the human survival and development, material needs are the most basic requirements, is the basic reason of people engaged in all social activities. Material incentive to employees' satisfaction with the basic requirements, and then affect their social status, social interaction and self-realization, satisfy the high requirements. Material incentives can by issuing wages, bonuses, allowances, benefits and other ways. After the material needs are met, people's demand to a higher level of development, namely the spiritual demand level. As a result, demand for in different stage of the staff, pure material incentive and spiritual incentive is difficult to achieve the desired effect, enterprise must combine material incentives and spiritual incentives can arouse the enthusiasm of staff. (3) Excellent enterprise culture to form a cohesive force of the enterprise, to motivate employees to create enthusiasm, cultivating employees to enterprise's identity and the casting with the enterprise spirit. Incentives play other management system. (4) Training is an important means of access to quality human resources, but also all the investment risk in the smallest and the largest strategic investment. (5) Enterprise for staff career planning, make full use of the promotion mechanism, can greatly arouse the enthusiasm of employees, can better keep enterprise to cultivate talents and attract more talents to join the enterprise.

The Combination of Humanism Management Thoughts and Positive Incentive. Management modernization is that with the continuous development of science and technology practice, in the enterprise management constantly absorbing the latest achievements and application of management science in the world, and the latest development of natural science and social science, make the enterprise management to adapt to the requirement of mass production, promoting the development of social productive forces forward. 
Both thought, organization, and system and methods and tools, is inseparable from the people. Therefore, humanistic management is the important material guarantee to modernize. People are usually hidden lots of talents and abilities, and how best to arouse the enthusiasm of employees to release the latent energy is the main task of the enterprise managers. Human capital as well as physical capital is not was born with, but through investment. Natural persons only mastered some knowledge and skills, to complete the natural person to the transformation of the human capital. Therefore, human capital is the social education and training of workers and to accept the opportunity cost value of condensate on workers.

Enterprise culture construction is to build a staff for the enterprise identity spirit of enterprise, the enterprise ethics and management concept. This requires the construction of enterprise attaches great importance to the spirit of enterprise and values, shaping corporate image, make the enterprise culture not only to attract staff and the vast majority of consumer recognition and praise highly.

\section{Conclusion}

In this paper, we conduct research on the applications of humanism management thoughts and positive incentive on contemporary enterprise management activities. The implementation of knowledge management is the complex system engineering. To successfully implement knowledge management, enterprise needs to the accumulation of a lot of the force, not just technology, the accumulation of knowledge, also need to management, enterprise culture and the quality of employees, etc. The accumulation of one side of the force, the enterprise knowledge management from management good oneself of the beginning of the document, and then establishes the enterprise knowledge portal and knowledge discovery system which could also be institution transference unfolding. We firmly believe that through the proposed methodology, the management and the development of the companies will be enhanced and promoted.

\section{References}

[1] Bian Y G, Guo K Z. A Definition of the Basic Structure of Enterprise Management Systems Based on Relationship Flow[J]. Journal of Guangdong University of Technology, 2014.

[2] Cai Y, Bureau S A. On Knowledge Management of Enterprise Archives Information[J]. Archives Science Study, 2014.

[3] Lin H. On the Power Supply Enterprise Asset Management Measures Implemented and the Approaches[J]. Science \& Technology \& Innovation,

2014 